\title{
Hemispheric asymmetry in the efficiency of attentional networks
}

\author{
Dariusz Asanowicz $^{\mathrm{a}, *}$, Anna Marzecováa ${ }^{\mathrm{a}}$, Piotr Jaśkowski ${ }^{\mathrm{b}, \dagger}$, Piotr Wolski ${ }^{\mathrm{a}}$ \\ ${ }^{a}$ Institute of Psychology, Jagiellonian University, Krakow, Poland \\ ${ }^{\mathrm{b}}$ Department of Psychology, University of Finance and Management, Warsaw, Poland
}

\section{A R T I C L E I N F O}

\section{Article history:}

Accepted 29 February 2012

Available online 2 April 2012

\section{Keywords:}

Attention

Attentional networks

Hemispheric asymmetry

Hemispheric specialization

Attentional asymmetries

Attention Network Test

\begin{abstract}
A B S T R A C T
Despite the fact that hemispheric asymmetry of attention has been widely studied, a clear picture of this complex phenomenon is still lacking. The aim of the present study was to provide an efficient and reliable measurement of potential hemispheric asymmetries of three attentional networks, i.e. alerting, orienting and executive attention. Participants $(N=125)$ were tested with the Lateralized Attention Network Test (LANT) that allowed us to investigate the efficiency of the networks in both visual fields (VF). We found a LVF advantage when a target occurred in an unattended location, which seems to reflect right hemisphere superiority in control of the reorienting of attention. Furthermore, a LVF advantage in conflict resolution was observed, which may indicate hemispheric asymmetry of the executive network. No VF effect for alerting was found. The results, consistent with the common notion of general right hemisphere dominance for attention, provide a more detailed account of hemispheric asymmetries of the attentional networks than previous studies using the LANT task.
\end{abstract}

(c) 2012 Elsevier Inc. All rights reserved.

\section{Introduction}

The organization of the human attentional system is one of the crucial issues for research on attention. A large body of evidence suggests that attentional networks are distributed asymmetrically across hemispheres and the right side of the brain is dominant for attention (Heilman, 1995; Mesulam, 1999; Posner \& Petersen, 1990). However, many studies have produced equivocal results, and some authors even suggest left rather than right hemisphere superiority in attention (cf. Kinsbourne, 1987). Hence, it is still not clear which specific aspects of attention are lateralized, and which of the hemispheres is indeed specialized in particular attentional functions.

\subsection{Hemispheric asymmetry of attentional networks}

Attention is often viewed as a system organized into three neural networks, which subserve three different types of functions: achieving and maintaining an alert state, orienting to sensory events, and resolving conflicts between alternative actions. Each of the attentional networks involves a number of anatomically separated but highly connected structures, which are largely distributed within the two hemispheres (Parasuraman, 1998; Posner \& Petersen, 1990; Posner \& Rothbart, 2007; Robertson, 2004). Below, we briefly describe the available evidence for the hemispheric asymmetry of each network.

\footnotetext{
* Corresponding author. Address: Institute of Psychology, Jagiellonian University, Al. Mickiewicza 3, Krakow, Poland. Fax: +48 126237699.

E-mail address: d.asanowicz@uj.edu.pl (D. Asanowicz).

† Deceased 6 January 2011.
}

\subsubsection{Alerting network}

A number of evidence has suggested that alertness is controlled mostly by the right frontal and parietal lobes (Fan, McCandliss, Sommer, Raz, \& Posner, 2002; Posner \& Petersen, 1990). Lesion studies have shown more severe impairment of alertness in right hemisphere-damaged patients (Fernandez-Duque \& Posner, 2001; Heilman, 1995), imaging studies have demonstrated that both processing an alerting cue and maintaining intrinsic alertness engage the right hemisphere $(\mathrm{RH})$ more strongly than the left (Fan et al., 2007; Sturm \& Willmes, 2001; Sturm et al., 1999; Sturm et al., 2005), and the LVF-RH advantage has been observed in behavioral visual half-field tasks that evoked alerting by presenting a lateralized warning cue (Heilman \& Van Den Abell, 1979), or required an endogenous maintenance of alertness (Whitehead, 1991). However, a recent fMRI study has reported a greater involvement of the left hemisphere in the processing of alerting cues (Fan, McCandliss, Fossella, Flombaum, \& Posner, 2005). Some authors believe that this discrepancy may result from differential specialization of the hemispheres, i.e. superiority of the LH in phasic alertness and the RH in tonic alertness (Okubo \& Nicholls, 2008; Posner, 2008). Nevertheless, the hypothesis of LH specialization in processing phasic or transient aspects of visual events, which underlies the notion of LH advantage in phasic alertness (cf. Posner, 2008), has been challenged by studies reporting LVF-RH advantage in tasks that required detection of fast subtle temporal changes (Funnell, Corballis, \& Gazzaniga, 2003), and identification of target stimuli in two lateralized streams of rapidly presented distractors (Verleger, Śmigasiewicz, \& Möller, 2011). Moreover, in two recent behavioral studies of attentional networks no asymmetry of the alerting effect was observed (Greene et al., 2008; Poynter, Ingram, 
\& Minor, 2010). Thus, firm conclusions regarding the organization and laterality of alerting network cannot be yet drawn.

\subsubsection{Orienting network}

There is an abundance of neuropsychological evidence for the right hemisphere's dominance in spatial orienting of attention. Particularly, hemispatial neglect, a syndrome of one-sided inattention, occurs in the vast majority of cases after right hemisphere lesions (Danckert \& Ferber, 2006; Mesulam, 1999). Neuroimaging and TMS studies of nonclinical populations also reveal greater involvement of the right hemisphere in distribution of attention within the left and right VFs (Chambers, Payne, Stokes, \& Mattingley, 2004; Corbetta, Miezin, Shulman, \& Petersen, 1993; Nobre et al., 1997). However, behavioral visual half-field studies of neurologically intact people do not show a consistent pattern of asymmetries in attentional orienting. Although some suggest the RH dominance, as indicated by a left visual field (LVF) advantage (Du \& Abrams, 2010; Evert, McGlinchey-Berroth, Verfaellie, \& Milberg, 2003; Greene et al., 2008, exp.1; Wainwright \& Bryson, 2005), others show either no asymmetry (Greene et al., 2008, exp.2; Losier \& Klein, 2004; Verfaellie, Bowers, \& Heilman, 1988) or even a right visual field (RVF) advantage (Nobre, Sebestyen, \& Miniussi, 2000; Reuter-Lorenz, Kinsbourne, \& Moscovitch, 1990; Rhodes \& Robertson, 2002). It seems that at least some of these discrepancies might be explained by the neuroanatomical model proposed by Corbetta and Shulman (2002), according to which we can distinguish two networks for orienting: the first, a bilaterally organized dorsal frontoparietal network that controls endogenous allocation of spatial attention for selection of relevant information, and the second, a ventral frontoparietal network that subserves reorienting to potentially relevant but currently unattended stimuli, which is localized mostly in the RH (Shulman et al., 2010). However, it is still not clear whether such hemispheric organization of the orienting networks does indeed lead to asymmetry in the distribution of attention between the visual fields on the behavioral level.

\subsubsection{Executive network}

Several authors have reported a smaller Stroop interference effect for LVF than for RVF in a lateralized version of the Stroop task (Franzon \& Hugdahl, 1987; Schmit \& Davis, 1974; Weekes \& Zaidel, 1996). The results seem to suggest a RH specialization in executive attention, although it has been pointed out that due to LH involvement in semantic processing (see MacLeod, 1991) they might rather reflect a greater interference in RVF. Still, an fMRI imaging study has shown greater right frontal activation during performance of the Stroop task (Milham et al., 2001) suggesting that the LVF advantage in behavioral tasks may indeed be due to RH dominance in attentional control of response conflict. The importance of the right prefrontal cortex and the right anterior cingulate cortex (ACC) in conflict resolution, and particularly in response inhibition, is further evidenced by a number of imaging studies employing non-verbal conflict tasks (Garavan, Ross, \& Stein, 1999; Goghari \& MacDonald, 2009; Hampshire, Chamberlain, Monti, Duncan, \& Owen, 2010; Hazeltine, Bunge, Scanlon, \& Gabrieli, 2003; Hazeltine, Poldrack, \& Gabrieli, 2000; Konishi et al., 1999; Lütcke \& Frahm, 2008), as well as by a TMS study (Chambers et al., 2007). It should be noted, however, that all the imaging studies employed foveal stimulation, unlike the behavioral Stroop experiments cited above. Central and lateralized stimulation may be processed in a different way and lead to different results. Thus, comparison of the two kinds of data should be made with caution. Moreover, there are still some unexplained discrepancies in the available results. For instance, Fan, Flombaum, McCandliss, Thomas, and Posner (2003) reported that three different visuospatial tasks involving cognitive conflict resulted in activation of two common structures: the left dorsal ACC and the left prefrontal cortex (unfortunately, the study did not provide detailed analyses of hemispheric asymmetry for each of the tasks). Further, a meta-analysis of VF effects in the behavioral lateralized Stroop task revealed only a non-significant trend for the LVF advantage in terms of effect magnitude (Belanger \& Cimino, 2002). Thus, in light of current knowledge we still cannot argue with satisfactory certainty whether the executive network is bilaterally organized, or whether the right hemisphere is specialized in attentional control of response conflict.

\subsection{Behavioral measures of attentional asymmetries}

As Zaidel (1995) noted, behavioral visual half-field methodology provides indirect measures of hemispheric asymmetries, which are inherently noisy. Indeed, the VF effects observed in studies on attention are typically small, volatile (see Hellige, Laeng, \& Michimata, 2010 for review of visuospatial asymmetries), and easily affected by a number of factors, such as stimulus properties (Chokron, Brickman, Wei, \& Buchsbaum, 2000; Polich, DeFrancesco, Garon, \& Cohen, 1990), fluctuations of alertness (Manly, Dobler, Dodds, \& George, 2005), age (Hausmann, Waldie, \& Corballis, 2003; Wainwright \& Bryson, 2005), hormonal changes (Hausmann, 2005), self-reported attentional deficits (Poynter et al., 2010), or reading direction (Eviatar, 1995; Spalek \& Hammad, 2005; but see Śmigasiewicz et al., 2010), to name only a few. A crucial issue was pointed out by Evert and colleagues (2003), who argued that the lack of behavioral evidence for asymmetry of attention in many studies is due to the insufficient attentional demands of the tasks employed. In accordance, the authors demonstrated that the cost of invalid cueing in Posner's task was lower for the LVF targets than for targets that occurred in the RVF, but the asymmetry was obtained only under conditions of high perceptual load, i.e. when targets were presented simultaneously with distractors, and thus more attentional effort was needed to differentiate the stimuli (Evert \& Oscar-Berman, 2001; Evert et al., 2003). Nonetheless, among many small and elusive effects, there is a notable exception: a large LVF advantage has been consistently shown in studies employing the lateralized Rapid Serial Visual Presentation (RSVP) task (Holländer, Corballis, \& Hamm, 2005; Verleger et al., 2009; Śmigasiewicz et al., 2010). In this task participants are asked to identify two consecutive targets embedded in two parallel streams of distractor stimuli presented simultaneously in the left and right VFs. The second target is identified up to 20-30\% more accurately if it occurs in the LVF. This indeed provides an important corroboration of the notion that only under high perceptual demands, like in the dual-stream RSVP task, the functional asymmetries become apparent. Otherwise, visual stimuli are salient enough to be processed with little effort, thus hemispheric specialization in attention is not revealed.

A reliable measurement of the attention networks' asymmetries seems therefore to require a task that imposes sufficiently high processing demands and is capable of addressing each of the three networks: alerting, orienting, and executive. Recently, Greene and colleagues (2008) employed a task that comes close to the specified requirements. They developed a lateralized version of the Attention Network Test (ANT; Fan et al., 2002). The ANT provides a behavioral measure of the efficiency of each attentional network. The lateralized ANT (LANT) additionally enables assessment of the networks' functioning in both hemispheres separately. Obviously, the LANT should be a useful tool to study hemispheric asymmetries, as well. However, Greene and associates did not find any asymmetries besides a marginally significant LVF advantage in orienting reported in the first experiment but unreplicated in the second (2008). The effect sizes and the reliability of the attentional networks indexes obtained by 
Greene et al. (2008) suggest that the task design might have not been sensitive enough to capture small VF effects. The indexes of alerting and orienting attention were less reliable in the study and accounted for less overall variance than the index of executive attention (for an analysis of the psychometric properties of the ANT see Macleod et al., 2010). Moreover, given the very high overall accuracy (>95\%; Greene et al., 2008), the attentional demands of the task may have been too low.

The aim of the present study was to provide more detailed and reliable behavioral evidence of functional asymmetries and hemispheric specialization in alerting, orienting and executive attention. To this end, the modified Lateralized Attention Network Test was employed. To capture small effects more reliably, we have made an effort to boost the signal-to-noise ratio, first, by enhancing statistical power using a greater number of both trials and participants; and second, by attempting to increase the effect itself using a more demanding task that would engage measured processes to a sufficient extent. The latter would be achieved by presenting stimuli more peripherally in the left and right VFs. With increased retinal eccentricity, visual acuity decreases and target discrimination requires more attention to boost the apparent stimulus contrast and clarity (cf. Abrams, Barbot, \& Carrasco, 2010; Carrasco, Ling, \& Read, 2004; see also Bourne, 2006). In line with Evert et al. (2003) and Verleger et al. (2009), the stronger attentional involvement may increase the reliability of assessing functional asymmetries of attention.

\section{Methods}

\subsection{Participants}

One hundred thirty undergraduate students participated in the experiment in return for course credits. Five of them were excluded from the analysis due to a very low accuracy approaching the chance level (50\%). The remaining sample $(N=125)$ consisted of 89 females and 36 males. The participants' mean age was 22.2 (SD 3.4). All but four persons reported right-handedness. The left-handers were included in the analyses because their performance did not differ from that of the right-handed participants. All had normal or corrected-to-normal vision and no history of neurological disorders.

\subsection{Lateralized Attention Network Test (LANT)}

The efficiency of alerting, orienting, and executive networks was assessed by the revised Lateralized Attention Networks Test (LANT), originally developed by Greene et al. (2008). The task is illustrated in Fig. 1. Participants were asked to indicate the direction of an up- or down-pointing arrow, displayed with equal probability on the left or right side of the screen. Speed and accuracy of responses were measured. In each trial, the arrow was flanked by four additional arrows (two above and two below), pointing in the direction that was either congruent or incongruent with the target arrow. In the incongruent condition, participants had to overcome the conflict elicited by the distractor arrows. The stimuli were preceded by a center cue to alert participants, or by a spatial cue to orient their attention; the orienting cue would be either valid, i.e. correctly indicating the location of the following target, or invalid (cf. Posner, 1980). Therefore, the alerting cue informed participants when the target would occur, whereas the orienting cue additionally informed them about the target location. A no-cue reference condition was also included. To increase the attentional demands of the task and to enhance its statistical power we extended the stimulus eccentricity from the $1.1^{\circ}$ to $5^{\circ}$ and increased the number of trials from 272 to 576 per subject, as compared to the original LANT. We also employed a sample roughly five times larger than in Greene et al.'s (2008) study.

\subsubsection{Stimuli and apparatus}

The target central arrow and the flankers were each $8 \mathrm{~mm}$ $\left(0.65^{\circ}\right)$ long. In total, the length of all arrows was $44 \mathrm{~mm}\left(3.6^{\circ}\right)$. They were displayed $62 \mathrm{~mm}\left(5^{\circ}\right)$ to the left or right of a $4 \mathrm{~mm}$ $\left(0.32^{\circ}\right)$ wide fixation cross, positioned centrally on the screen. An asterisk of $5 \mathrm{~mm}\left(0.4^{\circ}\right)$ diameter was used as a cue, being displayed either centrally at the position of the fixation cross (alerting cue), or laterally at the same position as the target (orienting cue). Stimuli were presented on a 17-in. computer display, via DMDX software (Forster \& Forster, 2003). Participants viewed the screen from a distance of about $70 \mathrm{~cm}$.

\subsubsection{Trial timeline}

The trial started with a fixation period of variable random duration (1600 to $2500 \mathrm{~ms}$ ) and was subsequently followed by a cue presented for $100 \mathrm{~ms}$, a short fixation period ( $400 \mathrm{~ms})$, and by a target with flankers presented for $180 \mathrm{~ms}$. In the no-cue condition the target was displayed immediately after the fixation period. The trial ended after the participant's response or, if a response was not made, after $2000 \mathrm{~ms}$. The fixation cross was displayed at the centre of the screen throughout the whole trial.

\subsubsection{Procedure}

The experiment consisted of 576 trials divided into 4 blocks of 144 trials each. On one half of the trials (288) the target was flanked by congruent flankers and on the other half by incongruent flankers. On 128 trials the target was signaled by the alerting cue. The no cue condition occurred on another 128 trials. On remaining trials, the target was preceded by the orienting cue that indicated the target's location with a probability of $80 \%$. To ensure a sufficient number of trials in the invalid cue condition the total number of trials with the orienting cue was increased to 320 (256 valid and 64 invalid). The order of the trials was randomized for each participant. The task started with a practice session, consisting of 2 blocks of 16 trials each, in which participants received feedback on the accuracy of each response. The whole experiment lasted up to one hour.

Instructions were given in written form and included an example of the stimuli. Participants were asked to maintain fixation throughout the whole trial and to respond to targets as quickly and accurately as possible. To ensure proper fixation, we utilized some frequently used methods (cf. Bourne, 2006; Hellige \& Sergent, 1986): a clear instruction emphasizing the importance of correct fixation, an adequate time interval of initial fixation, an unpredictable stimuli location (except for the orienting cue conditions due to the predictive character of the orienting cues), and the center alerting cue displayed in a number of trials, which, apart from its alerting function, also encouraged fixation at the center of the screen. Participants responded by pressing buttons on a computer mouse. To make responding easier and more natural, spatial compatibility of the response pattern and the direction of the arrows was ensured. The mouse was placed at midline, parallel to the screen. In this way the right and left buttons were positioned up and down. Participants were asked to press the upper button for the up-pointing targets, and the lower button for the down-pointing ones. When participants used their right hands, they used their middle finger to press the right button (i.e. the 'upper' button) for the targets pointing up and their index fingers to press the left (i.e. 'lower') button for the targets pointing down. For the left hand, the response mapping was reversed, i.e. the right button became the lower key, and the left button became the upper key. Thus, the mouse was turned by $180^{\circ}$ every time the subject switched hands. Response hands were alternated between the blocks. 


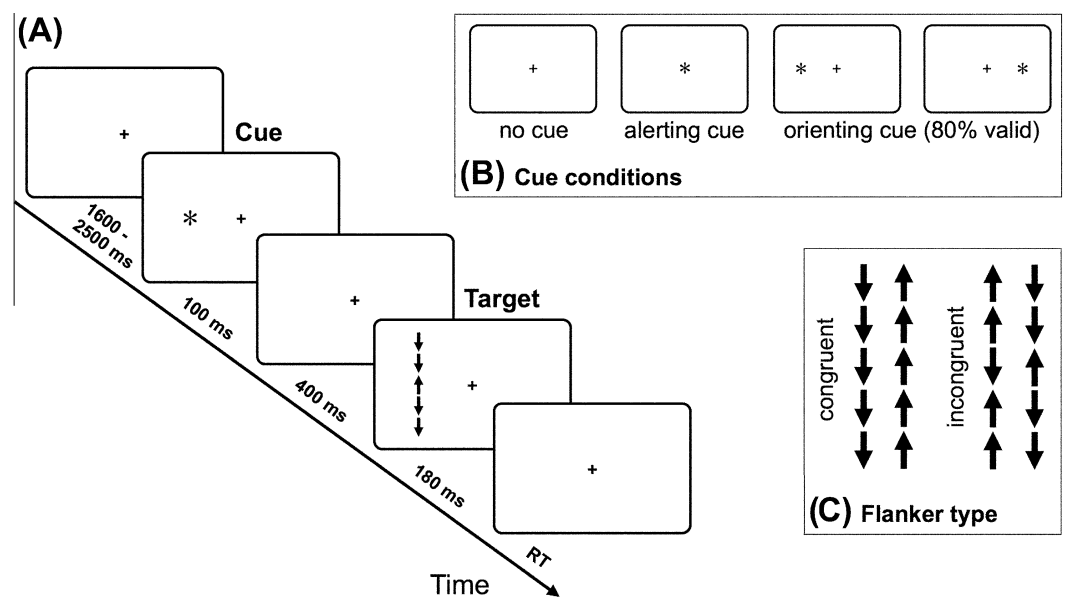

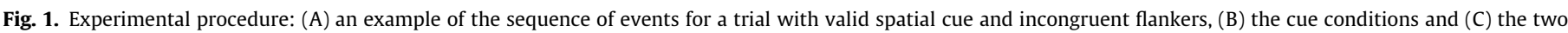
flanker types.

\subsection{Experimental design, operational definitions and data analysis}

The experiment followed a $4 \times 2 \times 2$ factorial design with cue condition (no cue/valid orienting cue/invalid orienting cue/alerting cue), flanker type (congruent/incongruent) and visual field (left/ right) as within-subject factors. Further, three separate subtractions were conducted to calculate indexes of the attentional networks (cf. Fan et al., 2002; Posner \& Rothbart, 2007). The alerting index (no cue minus alerting cue) shows the extent to which response to a target is improved by the alerting cue compared to the no cue condition (cf. Fan et al., 2002). The larger the score, in terms of both RT and ERR, the more efficient the alerting network. The orienting index (invalid cue minus valid cue) shows the difference in responses to a target that occurred at expected vs. unexpected location. Thus, a higher score can be interpreted as higher efficiency of orienting (cf. Callejas, Lupiáñez, \& Tudela, 2004; Posner, 1980). However, following the Corbetta and Shulman's (2002) model, orienting of attention is considered to be controlled by the two functionally separated systems, and further analyses including a full range of data is needed to interpret the potential VF asymmetries of the orienting index. For instance, a quicker or more accurate response to the left validly cued target than to the right one would indicate a higher efficiency of the RH dorsal orienting network, which controls the endogenous allocation and maintenance of spatial attention; whereas the LVF advantage in the invalid cue condition would indicate RH superiority in reorienting to unattended targets, which is controlled by the ventral frontoparietal network (cf. Corbetta, Patel, \& Shulman, 2008). To this end, additional analyses of variance were conducted (see Section 3.3). Finally, the index of executive network (incongruent flanker minus congruent flanker condition) reflects the cost of conflict or interference caused by incongruent flankers (Eriksen \& Eriksen, 1974; Fan et al., 2002). The larger the conflict index, in terms of both RT and ERR, the less efficient the network is in resolution of the conflict (Posner \& Rothbart, 2007). The reliability of the three indexes was estimated by split-half correlations between the first and second halves of the task.

\section{Results}

\subsection{Response times}

Trials with errors (13.5\%) and trials with response times (RT) less than $150 \mathrm{~ms}$ or greater than $1500 \mathrm{~ms}(0.4 \%)$ were excluded from the analysis. The overall mean RT for correct trials was $669 \mathrm{~ms}(\mathrm{SD}=74)$. Table 1 shows the averages for all conditions.
A $4 \times 2 \times 2$ repeated measures analysis of variance (ANOVA) was conducted on RTs with cue (no-cue/valid orienting/invalid orienting/alerting), flanker (congruent/incongruent) and visual field (LVF/RVF) as within-subject factors. All the main effects were significant. Response times differed between cue conditions $\left(F(3,372)=596.3, p<.0001, \eta^{2}=.82\right)$, with the fastest responses for trials preceded by a valid orienting cue $(575 \mathrm{~ms})$ and the slowest for invalidly cued trials (737 ms). (The effects of cues are analyzed further in Section 3.3, which describes the orienting and alerting networks separately.) Responses were much faster on congruent $(616 \mathrm{~ms})$ than on incongruent trials $(722 \mathrm{~ms})$, resulting in a significant index of conflict cost $(106 \mathrm{~ms}, F(1,124)=507.2$, $\left.p<.0001, \eta^{2}=.80\right)$. Responses to targets presented in the LVF were on average $7 \mathrm{~ms}$ faster than those presented in the RVF $\left(F(1,124)=9.0, p=.004, \eta^{2}=.065\right)$. Importantly, we found a significant interaction between cue and $\operatorname{VF}(F(3,372)=2.6, p=.049$, $\left.\eta^{2}=.021\right)$. A marked LVF advantage of $15 \mathrm{~ms}$ was observed in the invalid cue condition; for the alerting cue condition the advantage was $7 \mathrm{~ms}$, while in the no cue and valid cue condition RTs for both VFs were almost identical (see Fig. 2A). (Simple effects of the interaction are analyzed with regard to the alerting and orienting network separately and described in Section 3.3.) Furthermore, results revealed an asymmetry of conflict cost, as indicated by the interaction flanker type $\times \mathrm{VF} \quad(F(1,124)=3.9, \quad p=.049$, $\eta^{2}=.031$, Fig. 3A). Importantly, the observed LVF advantage was three times larger in the incongruent than in the congruent condition (10 vs. $3 \mathrm{~ms}$ ). When VF differences were analyzed separately for the congruent and the incongruent condition, the asymmetry turned out to be significant in the incongruent condition only $(t(124)=3.0, p=.003)$.

The interaction cue by flanker was significant $(F(3,372)=12.9$, $\left.p<.0001, \eta^{2}=.09\right)$, while cue $\times$ flanker $\times \operatorname{VF}$ was not $(F(3,372)=$ $\left.1.7, p=.17, \eta^{2}=.01\right)$. An additional ANOVA with two-level factors: cue (none/alerting), flanker (congruent/incongruent) and VF (left/ right) was computed on RTs to test for a possible influence of the alerting on the executive network, independently from the orienting network (trials with orienting cues that involved the orienting network were excluded). The interactions of cue $\times$ flanker $\left(F(1,124)=1.2, p=.27, \eta^{2}=.01\right)$, and cue $\times$ flanker $\times \operatorname{VF} F(1,124)=$ $0.34, p=.56, \eta^{2}=.003$ ) were both small and non-significant, showing no influence of the alerting on the executive network, and no VF effects. Therefore, the interaction of 4 cue conditions $\times 2$ flanker types found in the first ANOVA reflects the effect of orienting rather than alerting on the executive network. A $2 \times 2$ ANOVA, with cue (valid orienting/alerting) and flanker (congruent/incongruent) as factors, confirmed that the valid orienting cue 
Table 1

Mean response times of correct responses and error rates for all conditions.

\begin{tabular}{|c|c|c|c|c|c|c|}
\hline Cue condition & Flanker type & Visual field & $\mathrm{RT}(\mathrm{ms})$ & $(\mathrm{SD})$ & $\operatorname{ERR}(\%)$ & $(\mathrm{SD})$ \\
\hline \multirow[t]{4}{*}{ No cue } & \multirow[t]{2}{*}{ Congruent } & Left & 647.4 & $(73.6)$ & 3.0 & $(4.4)$ \\
\hline & & Right & 647.8 & $(77.2)$ & 3.3 & $(4.8)$ \\
\hline & \multirow[t]{2}{*}{ Incongruent } & Left & 760.2 & $(90.6)$ & 28.6 & $(17.5)$ \\
\hline & & Right & 764.5 & (92.9) & 34.4 & $(21.8)$ \\
\hline \multirow[t]{4}{*}{ Valid orienting } & \multirow[t]{2}{*}{ Congruent } & Left & 528.6 & $(68.1)$ & 1.3 & $(3.0)$ \\
\hline & & Right & 529.8 & (67.1) & 1.5 & $(2.9)$ \\
\hline & \multirow[t]{2}{*}{ Incongruent } & Left & 617.9 & $(97.1)$ & 9.0 & (12.0) \\
\hline & & Right & 624.5 & (99.7) & 10.4 & $(14.8)$ \\
\hline \multirow[t]{4}{*}{ Invalid orienting } & \multirow[t]{2}{*}{ Congruent } & Left & 684.2 & (98.7) & 7.5 & $(9.6)$ \\
\hline & & Right & 690.4 & $(97.4)$ & 8.9 & $(9.4)$ \\
\hline & \multirow[t]{2}{*}{ Incongruent } & Left & 775.7 & $(105.0)$ & 30.4 & $(21.6)$ \\
\hline & & Right & 800.3 & (126.7) & 36.4 & $(22.4)$ \\
\hline \multirow[t]{4}{*}{ Alerting (center) } & \multirow[t]{2}{*}{ Congruent } & Left & 596.1 & $(70.4)$ & 1.4 & $(3.1)$ \\
\hline & & Right & 602.5 & (74.8) & 2.3 & $(3.7)$ \\
\hline & \multirow[t]{2}{*}{ Incongruent } & Left & 714.6 & $(81.9)$ & 17.0 & (15.9) \\
\hline & & Right & 720.9 & $(92.9)$ & 20.4 & $(18.8)$ \\
\hline
\end{tabular}

invalid cue $\bullet$ no cue $\_$center cue $\bullet$ valid cue

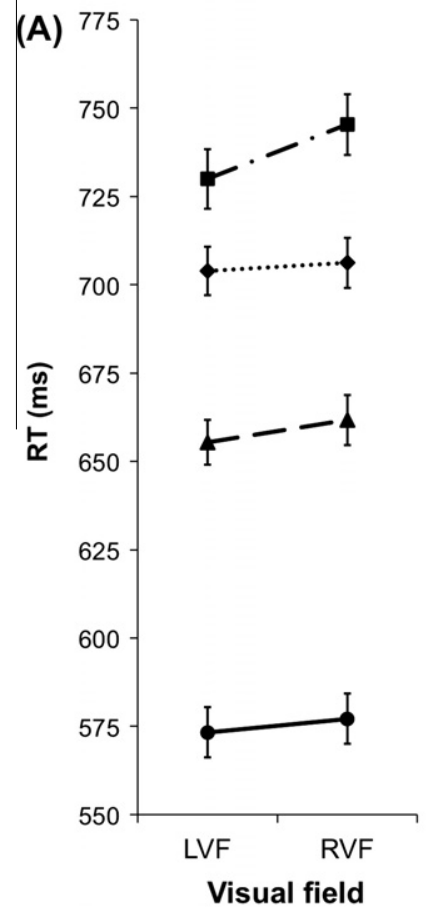

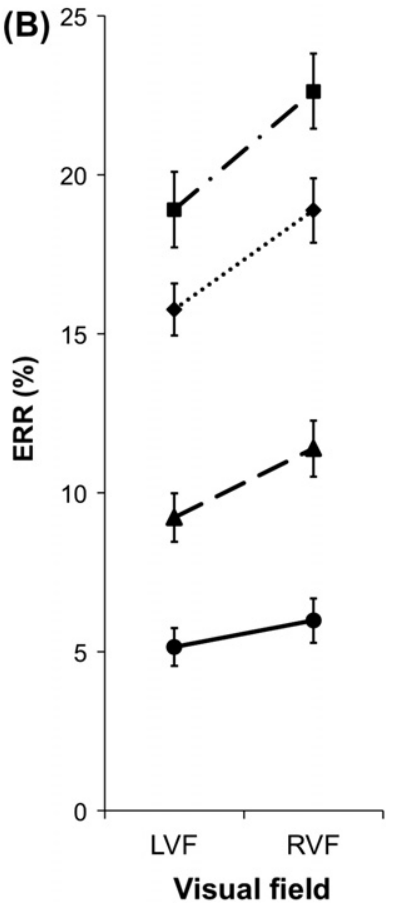

Fig. 2. Cue condition by VF interaction in terms of RT (A) and ERR (B). Error bars represent standard errors of the mean.

significantly decreased the cost of conflict, as compared to the conflict score obtained in the alerting cue condition $(F(1,124)=68.5$, $\left.p<.001, \eta^{2}=.35\right)$. The interaction between cue, flanker and VF was insignificant $\left(F(1,124)=1.0, p=.32, \eta^{2}=.008\right)$.

\subsection{Error rates}

The overall error rate (ERR) yielded 13.5\% ( $S D=7.9$ ). As expected, the task was more difficult than the previous implementations of ANT and LANT, in which the error rates were less than 5\% (cf. Fan et al., 2002; Greene et al., 2008). Hence, the accuracy measure was less prone to a ceiling effect. Table 1 presents the ERRs for all conditions.

Just as with the RT data, we started the ERR analysis with a $4 \times 2 \times 2$ ANOVA. The results matched the RT ANOVA quite closely. The main effect of cue $\left(F(3,372)=159.7, p<.0001, \eta^{2}=.56\right)$ was

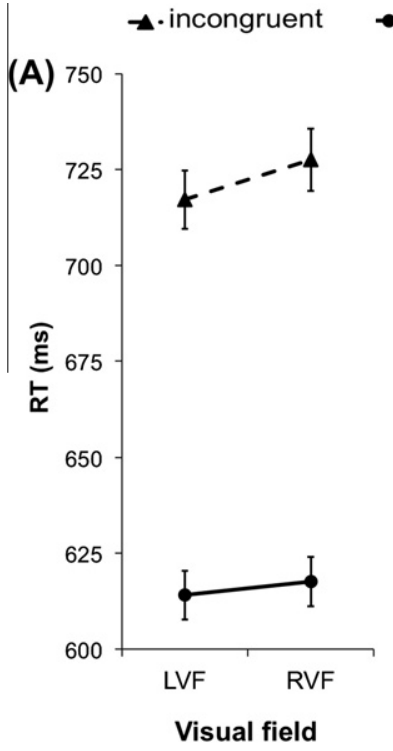

congruent

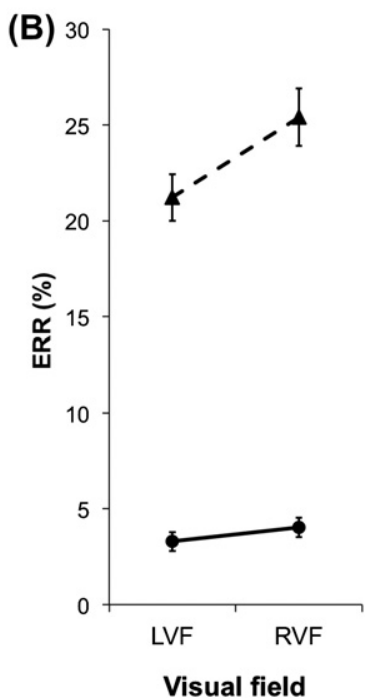

Fig. 3. Flanker type by VF interaction in terms of RT (A) and ERR (B). Error bars represent standard errors of the mean.

highly significant. Accuracy was highest in the valid orienting cue condition (ERR $=5.5 \%$ ), lower in the alerting cue $(10.3 \%$ ) and no-cue conditions (17.3\%), and lowest in the invalid orienting cue condition (20.7\%). ERR was much smaller in the congruent flanker condition than in the incongruent flanker condition, as confirmed by the significant main effect of the flanker type (3.6 vs. $23.3 \%$, $\left.F(1,124)=242.5, p<.0001, \eta^{2}=.66\right)$. We also observed a clear asymmetry: ERR was lower in the LVF than in the RVF (12.2 vs. $14.7 \%$ respectively, $\left.F(1,124)=30.0, p<.0001, \eta^{2}=.19\right)$. The LVF advantage was modified by occurrence of the cues, as indicated by the cue condition $\times \mathrm{VF}$ interaction $(F(3,372)=4.2, p=.006$, $\eta^{2}=.033$; see Fig. 2B). When the location of the target was validly cued ERRs were similar for both VFs, but when the target was preceded by the invalid orienting cue, and thus reorienting of attention was needed, then the largest asymmetry was observed (see Section 3.3 for analyses of the simple effects of the interaction with regards to alerting and orienting separately). VF asymmetry also varied as a function of congruency, as confirmed by the significant flanker type $\times$ VF interaction $\left(F(1,124)=14.6, p<.0001, \eta^{2}=.10\right.$, see Fig. 3B). In the congruent condition, the ERRs were almost equal for both VFs (RVF-LVF $=0.7 \%$ ), while in the conflict condition VF asymmetry was markedly greater (RVF-LVF $=4.2 \%$ ). 
The remaining interactions were also significant: cue $\times$ flanker $\left(F(3,372)=106.9, \quad p<.0001, \quad \eta^{2}=.46\right)$ and cue $\times$ flanker $\times$ VF $\left(F(3,372)=3.0, p=.028, \eta^{2}=.02\right)$. Separate three-factor ANOVAs were computed for alerting and for orienting. The cue factor levels in the former were: none/alerting, and in the latter: valid orienting /alerting. The remaining two factors were the same in both analyses: flanker (congruent/incongruent), and VF (left/right). Both the alerting cue and valid orienting cue significantly reduced the conflict cost (respectively: $F(1,124)=103.5, p<.0001, \eta^{2}=.45$; and $\left.F(1,124)=95.2, p<.0001, \eta^{2}=.43\right)$. The three-way interaction: cue $\times$ flanker $\times$ VF was significant for alerting $(F(1,124)=4.1$, $\left.p=.043, \eta^{2}=.03\right)$, but not for orienting $(F(1,124)=1.8, p=.18$, $\left.\eta^{2}=.01\right)$.

\subsection{Attentional networks}

\subsubsection{Effects of alerting}

The effect of alerting, calculated as the difference in RT between the alerting cue and no-cue conditions, yielded $46.4 \mathrm{~ms}$ ( $\mathrm{SD}=26$, $t(124)=19.8, p<.001)$. A similar effect was obtained for the ERR: the alerting cue decreased the ERR by $7 \%(S D=6, t(124)=12.6$, $p<.001)$. No significant effects of VF were observed either for the RT $\left(F(1,124)=1.2, p=.27, \eta^{2}=.01\right)$, or the $\operatorname{ERR~}(F(1,124)=1.5$, $\left.p=.21, \eta^{2}=.01\right)$.

\subsubsection{Effects of orienting}

The orienting effect was assessed by calculating the difference between the valid and invalid cue conditions (Fan et al., 2009; Posner, 1980). The index was $162 \mathrm{~ms}$ for the RT (SD $=67$, $t(124)=26.8, p<.001)$ and $15.2 \%$ for the ERR $(S D=11.2$, $t(124)=15.2, p<.001)$. The interaction between cue condition (valid/invalid) and VF was marginally significant for the RT $\left(F(1,124)=3.3, p=.070, \eta^{2}=.026\right)$ and highly significant for the ERR $\left(F(1,124)=8.8, p=.004, \eta^{2}=.066\right)$. Importantly, in the valid cue condition, the RVF-LVF difference yielded only $4 \mathrm{~ms}$ in the RT and $0.8 \%$ in the ERR, whereas in the invalid cue condition, the LFV advantage was considerably larger and reached $16 \mathrm{~ms}$ for the RT (LVF vs. RVF: $F(1,124)=5.9, p=.017, \eta^{2}=.045$ ) and $3.7 \%$ for the ERR (LVF vs. RVF: $F(1,124)=13.5, p<.001, \eta^{2}=.10$ ). Thus, the reorienting to invalidly cued targets was more efficient for the targets presented in the LVF. These results are in line with the data of Evert et al. (2001, 2003), who reported VF asymmetry only for the invalid cue condition of Posner's cueing task.

\subsubsection{Effects of conflict}

The conflict cost was calculated by subtracting RTs and ERRs in the congruent from the incongruent flanker condition. The index, equivalent to the main effect of the flanker type described in Sections 3.1 and 3.2, reflects the efficiency of the executive network in conflict resolution. The mean conflict cost was $106.4 \mathrm{~ms}$ for the RT (SD $=52, t(124)=22.5, p<.001)$, and $19.6 \%$ for the ERR $(S D=14.1, t(124)=15.5, p<.001)$. The effect was larger in the RVF than in the LVF by $7 \mathrm{~ms}$ in the RT $(F(1,124)=3.96$, $\left.p=.049, \eta^{2}=.03\right)$, and by $3.5 \%$ in the $\operatorname{ERR}(F(1,124)=14.6$, $\left.p<.001, \eta^{2}=.10\right)$. Both $\mathrm{VF}$ effects are equivalent to flanker type $\times$ VF interactions described in Section 3.1 (see Fig. 3).

To exclude the possibility that the asymmetry in conflict resolution is somehow related to the asymmetry obtained in the invalid cue condition, additional ANOVAs were conducted with flanker and VF as within-subject factors for trials in the valid cue condition only. We found marginally significant interactions for the RT $\left(F(1,124)=3.14, p=.07, \eta^{2}=.025\right)$ and for the $\operatorname{ERR}(F(1,124)=3.5$, $\left.p=.06, \eta^{2}=.027\right)$. Separate tests of VF effects for the valid cue/congruent flanker and for the valid cue/incongruent flanker conditions revealed no effects for congruent trials, but a significant LVF advantage for incongruent trials, both in the RT (RVF-LVF $=6.5 \mathrm{~ms}$; $t(124)=2.2, p=.030)$ and the ERR (RVF-LVF $=1.4 \% ; t(124)=2.4$, $p=.018)$. Importantly, the analyses also did not reveal any VF effects for endogenous selection, when separated from the conflict condition (i.e. for the valid cue/congruent flanker trials).

\subsubsection{Split-half correlations}

To assess the reliability of the three indexes we computed Pearson correlations for response latencies between the first and the second halves of the task across all subjects, as did Fan et al. (2002) and Greene et al. (2008). Because our accuracy data were well below ceiling to allow for meaningful reliability analysis, we also computed split-half correlations for the error rates. The results are presented in Table 2 . The reliability of the orienting and conflict indexes was similar to that of the original ANT (Fan et al., 2002), with the exception of the alerting, which was relatively less reliable in our study. Importantly, the revised LANT provided overall more reliable RT indexes for all three networks than the original LANT (Greene et al., 2008). The split-half correlations for error rates were even higher, especially for the executive network's score.

\section{Discussion}

The objective of the present study was to investigate the functional hemispheric asymmetry of attentional networks. We found the LVF advantage in the invalid orienting cue condition, which suggests greater efficiency of the right hemisphere in reorienting of attention. The LVF advantage was also observed in the incongruent flanker condition, which may indicate the right hemisphere's dominance in resolution of conflict. The effects of alerting and endogenous selection did not differ across the VFs. In line with our expectations, the modified Lateralized Attention Network Test put more demands on attentional resources than both the ANT

\section{Table 2}

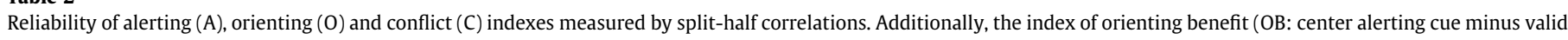

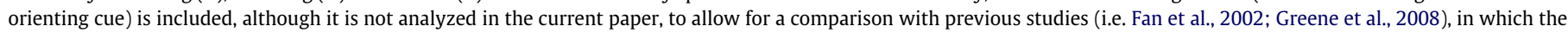
orienting index (invalid orienting cue minus valid orienting cue) was not calculated.

\begin{tabular}{|c|c|c|c|c|c|c|c|c|}
\hline & & \multicolumn{3}{|c|}{ LANT (current study) } & \multicolumn{3}{|c|}{ LANT (Greene et al., 2008; exp.2) } & \multirow[t]{2}{*}{ ANT (Fan et al., 2002) } \\
\hline & & Overall & LVF & RVF & Overall & LVF & RVF & \\
\hline \multirow[t]{4}{*}{ RT } & A & $.22^{*}$ & .09 n.s. & .13 n.s. & .18 n.s. & .32 n.s. & -.10 n.s. & $.52^{* *}$ \\
\hline & OB & $.65^{* * *}$ & $.59^{* * *}$ & $.52^{* * *}$ & $.47^{*}$ & $.39^{*}$ & $.40^{*}$ & $.61^{* *}$ \\
\hline & 0 & $.67^{* * *}$ & $.63^{* * * *}$ & $.45^{* * *}$ & - & - & - & - \\
\hline & C & $.67^{* * *}$ & $.57^{* * *}$ & $.56^{* * *}$ & $.64^{* * *}$ & .34 n.s. & $.67^{* * * *}$ & $.77^{* *}$ \\
\hline \multirow[t]{4}{*}{ ERR } & A & $.36^{* * *}$ & $.18^{*}$ & $.28^{* *}$ & - & - & - & - \\
\hline & OB & $.54^{* * *}$ & $.31^{* * *}$ & $.44^{* * * *}$ & - & - & - & - \\
\hline & 0 & $.65^{* * *}$ & $.52^{* * *}$ & $.54^{* * * *}$ & - & - & - & - \\
\hline & C & $.84^{* * * *}$ & $.77^{* * * *}$ & $.82^{* * *}$ & - & - & - & - \\
\hline
\end{tabular}

\footnotetext{
${ }^{*} p<.05$.

** $p<.01$.

*** $p<.001$.
} 
(Fan et al., 2002) and the original LANT (Greene et al., 2008), as evidenced by higher incidence of errors. Importantly, the RT and ERR analyses yielded similar and equally reliable results. By that means, the present task allowed us to detect the attentional asymmetries. This is in accordance with the assumption that if a particular mechanism of information processing is characterized by an asymmetrical pattern of hemispheric specialization, the asymmetry will become most evident in tasks requiring strong involvement of such a mechanism. Otherwise, the processing of stimuli is likely to be easy with no need for dedicated and specialized systems (cf. Evert et al., 2003; Verleger et al., 2009). However, it should be noted that although this notion has already been evidenced by Evert and colleagues (2003) in a study using Posner's cueing task, in case of the LANT, it is supported only by the indirect comparison of the present and previous studies, which limits the strength of our conclusions. Besides, the present study also brought interesting findings on the relationship between the networks, showing that the alerting cue may improve the accuracy of conflict resolution, but does not influence its speed. This finding conflicts with previous studies, in which alerting was shown to impair executive functions (Callejas, Lupiáñez, Funes, \& Tudela, 2005; Callejas et al., 2004). Further, we corroborated previous evidence showing that the valid orienting cue may improve resolution of conflict (cf. Callejas et al., 2004; Callejas et al., 2005; Lupiáñez \& Funes, 2005). Taken together, the results suggest that the current version of LANT allows for a reliable assessment of the functional hemispheric asymmetry of attentional networks in terms of both the response time and accuracy.

\subsection{LVF advantage in reorienting of attention}

If a cue indicates the target location with a high probability (e.g. $80 \%$ ), attention is endogenously oriented to the location and engaged on it until the target appears. Thus, when the target appears at a different, unattended location (invalid cue condition), attention needs to be reoriented (Corbetta \& Shulman, 2002; Posner, 1980 ). In the present study, we found the LVF advantage in reorienting to invalidly cued targets and no VF asymmetry for the endogenous selection of the targets in the valid cue condition. The results are similar to previous behavioral findings (Evert et al., 2001, 2003) and conform to the evidence that the ventral reorienting network is strongly right lateralized. According to the model proposed by Corbetta \& Shulman (2002, see also Corbetta et al., 2008), reorienting to an unexpected but behaviorally relevant stimulus that appears outside the current focus of attention transiently engages the ventral frontoparietal network, including the temporo-parietal junction (TPJ) and regions of the ventral frontal cortex (VFC), whereas the endogenous allocation of attention to select an object or location produces sustained activation of the dorsal frontoparietal network, particularly in the intraparietal sulcus (IPS) and regions of the frontal eye field (FEF). Crucially, the ventral reorienting network is strongly lateralized to the right hemisphere (Chambers et al., 2004; Fox, Corbetta, Snyder, Vincent, \& Raichle, 2006; Kim et al., 1999; Natale, Marzi, \& Macaluso, 2010; Shulman et al., 2010; although see Macaluso \& Patria, 2007), whereas the dorsal network is bilaterally organized (Corbetta, Kincade, Ollinger, McAvoy, \& Shulman, 2000; Fox et al., 2006; Hopfinger, Buonocore, \& Mangun, 2000; Shulman et al., 2010; Vandenberghe et al., 2000). Therefore, the model seems to predict a LVF advantage in the invalid cue condition and no asymmetry in the valid cue condition, which is in accordance with our results.

Another common model of spatial attention asymmetries, derived mostly from the lesion studies, suggests that the left hemisphere directs attention only to the contralateral VF, whereas the right hemisphere controls attention in both VFs (Heilman \& Van Den Abell, 1980; Mesulam, 1981). Although this model accounts well for the symptoms of hemispatial neglect, it does not seem to explain the LVF advantage in healthy subjects. In fact, the model might suggest the right rather than the left VF advantage, based on the hypothesis that the RVF is over-controlled or over-attended by both hemispheres (see Siman-Tov et al., 2007 for a similar notion). Thus, it does not seem to fit our data. Moreover, as Corbetta, Kincade, and Shulman (2002) pointed out, despite some early conforming results (Corbetta et al., 1993), brain-imaging studies generally do not support the model (Corbetta et al., 2000; Hopfinger et al., 2000; Woldorff et al., 2004). An alternative view, which emphasizes the asymmetry of interhemispheric transfer, was proposed by Siman-Tov and colleagues (2007). The results of their imaging study support the notion of right hemisphere specialization for attention, but also suggest that the ability to direct attention toward both hemifields is not exclusive to the right hemisphere, because both hemispheres were activated by the contralateral, as well as by the ipsilateral stimuli. Furthermore, the study revealed an overall LVF superiority, as the frontoparietal attentional network was more strongly activated in both hemispheres by the stimuli presented in the left hemifield. The authors conclude that, first, the hemispheres could exert attentional control over the visual fields contralaterally through direct pathways, as well as ipsilaterally through interhemispheric connections; and second, the right hemisphere specialization in attention and the stronger right-to-left than left-to-right interhemispheric connections altogether result in the overall LVF advantage in attentional processing (Siman-Tov et al., 2007; see also Okon-Singer et al., 2010). The idea of asymmetrical interhemispheric interactions in the attentional processing had been already proposed by Kinsbourne (1987); however, Kinsbourne's view assumed a mutual interhemispheric inhibition, not facilitation, as well as a stronger rightward bias produced by the left hemisphere (Reuter-Lorenz et al., 1990). Thus, we should again expect a right rather than left VF advantage, which is not the case in our study. The LVF advantage is instead predicted by the Siman-Tov et al.'s (2007) model, which, however, does not seem to offer a fully coherent explanation of the differential VF effects that we observed under the valid and invalid orienting cue conditions. In conclusion, although some involvement of asymmetric interhemispheric interaction cannot be ruled out, the Corbetta and Shulman's (2002) model seems to be the best fitting explanation of the present results.

\subsection{LVF advantage in conflict resolution}

The LVF advantage in conflict resolution was slightly larger than the effect of reorienting, and was present across all cue conditions. What is then the mechanism underlying the asymmetry in resolution of conflict? Imaging studies quite consistently show greater involvement of the right prefrontal regions in tasks requiring response control, particularly response inhibition, which is crucial in resolution of the flanker-type conflict (Bunge, Dudukovic, Thomason, Vaidya, \& Gabrieli, 2002; Garavan, Ross, Murphy, Roche, \& Stein, 2002; Garavan et al., 1999; Konishi et al., 1999; Lütcke \& Frahm, 2008; Milham et al., 2001; although see Fan et al., 2003). For instance, Hazeltine et al. (2003) showed that conflict resolution in different variants of the flanker task was, independently of stimulus material, associated with activation of the right ventrolateral prefrontal cortex, along with the right ACC. Numerous studies show specifically the right inferior frontal cortex involvement in response inhibition (Bunge et al., 2002; Hazeltine et al., 2000; Sharp et al., 2010; see Aron, Robbins, \& Poldrack, 2004 for review). Hence, the hypothesis of lateralization of the network involved in response inhibition or response conflict resolution seems to be well grounded (see Aron et al., 2004; Chikazoe, Konishi, Asari, Jimura, \& Miyashita, 2007; Levy \& Wagner, 2011; Vanderhasselt, De Raedt, \& Baeken, 2009 for review). The idea of 
a 'hard-wired' executive attention asymmetry gets further support from findings of a greater gray matter volume in the right ACC than in the left ACC (Huster, Westerhausen, Kreuder, Schweiger, \& Wittling, 2007; Paus et al., 1996). The evidence for stronger intrahemispheric functional connectivity within the right hemisphere, e.g. between the ACC and the DLPFC (Yan et al., 2009), also supports the hypothesis.

The notion of right hemisphere specialization in response control does not necessarily contradict the findings of Fan et al. (2003), which revealed activation of two nodes of a domain-general control system that was in common to three different types of conflict tasks: the left middle frontal gyrus and the left dorsal ACC. A frequently observed bilateral activation of frontal regions, or even a left hemisphere advantage during performance of different types of conflict tasks may occur due to the involvement of a broad range of control processes, with a particular demand for working memory. A number of studies emphasize the role of the left PFC, especially the left DLPFC and VLPFC, in the control of working memory and maintenance of a task-set (see Badre \& Wagner, 2007; Vanderhasselt et al., 2009 for review).

Although the observed LVF advantage in conflict resolution conforms to the hypothesis of right hemisphere predominance in response inhibition, the question of how the asymmetry of neural network affects behavioral performance yet remains to be answered. Assuming that: (1) the ACC constitutes the primary mediation for other structures (like the DLPFC and IFC) in monitoring, detection and resolution of conflict (Botvinick, Cohen, \& Carter, 2004; Posner, Sheese, Odludas, \& Tang, 2006); (2) response conflict engages the right ACC more than the left (e.g. Hazeltine et al., 2003); and (3) the right ACC has a greater connectivity strength with other regions in the right hemisphere than in the left (Yan et al., 2009); it is then plausible that the transfer of information would be faster and more efficient in case of RH conflict than LH conflict. This might hold true for the transfer of sensory information into the ACC from the right visual cortex (thus from the LVF), as well as for the transfer from the right ACC to the prefrontal structures that exert executive control to resolve response conflict, especially to the right prefrontal regions specialized in response inhibition (Aron et al., 2004; Vanderhasselt et al., 2009). Such a scenario might explain the LVF advantage in the resolution of response conflict, thus it needs to be put to the test in future studies.

\subsection{Alerting network and hemispheric specialization}

The alerting cue greatly accelerated response speed and accuracy when compared to the no-cue condition. However, no VF asymmetry was found for the alerting effect ${ }^{1}$. The lack of VF asymmetries in alertness might be due to the generally lower reliability of the alerting index - the apparent limitation of the LANT (also observed in the previous study by Greene et al., 2008). However, an alternative explanation may be derived, given the particular characteristics of alerting processes and specificities of the experimental procedure.

Alerting seems to involve at least two components in achieving and maintaining a state of readiness to process stimuli (Posner, 2008). The first, referred to as phasic alertness, is related to fast, exogenous and nonspecific activation, which can be evoked by any object, such as the alerting cue, or by the target itself if it is not signaled by any cue (Fernandez-Duque \& Posner, 2001). The second component, tonic alertness or vigilance, can be defined as a sustained activation which allows readiness to be

\footnotetext{
${ }^{1}$ It might be argued that the alerting cue, which is presented centrally, thus processed by both hemispheres, could be the reason for the lack of VF asymmetry. However, if the alerting network is lateralized, no matter how the network becomes activated, the asymmetry should affect the processing of following lateralized targets.
}

achieved and maintained endogenously; for example, if a person expects a target to appear at a particular moment in time (see Correa, 2010), or has to maintain a state of readiness in the absence of a cue (Posner, 2008). Possibly, the alerting index in the LANT (no-cue minus alerting cue) is a joint measure of both components of alertness entangled. The alerting cue automatically evokes phasic alertness, but also produces sustained activation, because of the precise information about the onset of the target provided by the cue (SOA was fixed at $500 \mathrm{~ms}$, similar to the previous studies with the ANT: Fan et al., 2002; Greene et al., 2008). As we noted in the introduction, several authors suggest that phasic alerting engages the left hemisphere to a larger extent, whereas the tonic alerting is rather right lateralized (Coull, Frith, Büchel, \& Nobre, 2000; Okubo \& Nicholls, 2008; Posner, 2008; Sturm \& Willmes, 2001). If the alerting index reflects both mechanisms, opposite lateralization effects for these two are likely to cancel each other out. However, some findings suggest that both aspects of alerting might be right lateralized (see Posner \& Petersen, 1990), and the hypothesis of LH dominance in phasic aspects of alertness might be questioned (cf. Funnell et al., 2003; Verleger et al., 2011). It has also been pointed out that common brain areas are engaged in both types of the alerting processes (Posner, 2008; Sturm \& Willmes, 2001; see also Fernandez-Duque \& Posner, 2001). Thus, our interpretation of the lack of VF asymmetry in alerting must be considered only as a hypothesis that is in need of further examination. Yet another possibility, which would need to be further explored, is that the alerting index, due to the fixed cue-target onset asynchrony and the relatively long SOA interval $(500 \mathrm{~ms})$, may not reflect the effect of alerting per se but rather a response preparation (cf. Fan et al., 2007) or an endogenous temporal orienting (cf. Correa, 2010).

\subsection{Attentional vs. perceptual asymmetries}

The asymmetries observed in the current study might be alternatively interpreted in terms of perceptual, rather than attentional mechanisms. There are at least two noteworthy accounts that may be put forward. The first one is derived from the spatial frequency model proposed by Sergent (1983b), which claims that the right hemisphere is specialized for the processing of visual information carried by low spatial frequencies, whereas the left hemisphere is more efficient in processing of visual features represented by high spatial frequencies. Low frequencies constitute a global structure or overall configuration, and high frequencies constitute smaller, local details of stimuli (see Christman, 1989; Grabowska \& Nowicka, 1996; for review). In accordance with the model, it has been shown that identification of a small target surrounded by flanking stimuli (local processing) results in the RVF-LH advantage, whereas a large single target (global processing) is better identified when presented to the LVF-RH (Chokron et al., 2000; Chokron et al., 2003; Tabert et al., 2000; see also Martin, 1979 for similar results from the Navon task). It has also been shown that not only the available range of input's spatial frequencies, but also - or even mainly - specific task requirements determine an obtained pattern of asymmetry, because they impose focus on either global or local features of stimuli, depending on what is needed for effective task performance. (Kitterle, Hellige, \& Christman, 1992; Sergent, 1983b). Therefore, flanker-type tasks (including the LANT) seem to primarily involve the local processing due to the structure of stimuli themselves, as well as due to the specificity of the task (a small target needs to be differentiated among flankers). Nevertheless, our study revealed the LVF advantage, instead of the RVF, which indicates that the effect is not related to the hemispheric asymmetry in global-local processing. It should be also noted that the lack of global-local asymmetry has been already reported in a number of studies (Boles \& Karner, 1996; Chiarello, Senehi, \& 
Soulier, 1986; Grabowska, Nowicka, \& Szatkowska, 1992. Polich \& Aguilar, 1990). Christman (1989) argued that the perceptual asymmetries may be overridden by stronger, more reliable effects such as the lateralization of verbal processing, if a task puts such requirements. Similarly, we believe that in the current study the attentional asymmetries overrode the perceptual effects. If this is the case, we may even speculate that the LVF advantage would have been larger, but it was somewhat reduced by the left hemisphere superiority for local processing.

The second account is based on a visibility hypothesis that claims greater efficiency of the right hemisphere during the initial, early visuospatial processing of perceptually degraded stimuli (Grabowska \& Nowicka, 1996; Hellige \& Webster, 1979). It has been shown that a degradation of stimuli visibility by increasing the retinal eccentricity of input or decreasing its exposure duration may impair LVF-RH processing to a lesser extent than RVF-LH processing, and thus lead to the LVF advantage (Boles \& Karner, 1996; Bradshaw, Hicks, \& Rose, 1979; Hellige, 1980; Polich, 1978; Rizzolati \& Buchtel, 1977; Sergent, 1983a). It seems that the stimuli duration would not affect the asymmetry in the current study, because the VF effect of short exposure duration is observed only if stimuli are presented for less than $100 \mathrm{~ms}$ (Blanca, Zalabardo, Gari-Criado, \& Siles, 1994; Hellige \& Webster, 1979; Sergent, 1983a), whereas in our task target duration was $180 \mathrm{~ms}$. Yet, the increased retinal eccentricity of the stimuli may be considered as a factor relevant to the observed LVF advantage. There are, however, at least two premises suggesting that this may not be the case. First, the increased eccentricity of stimuli does not necessarily result in the LVF advantage (Beaton \& Blakemore, 1981; Chiarello et al., 1986; Finlay \& Jenkins, 1980; Levy-Schoen, 1977; Marzi, Natale, \& Anderson, 2002), and may even lead to an opposite effect, i.e. the RVF advantage (Christman, 1987; Hellige, Corwin, \& Jonsson, 1984); hence, such inconsistent evidence should not be considered as an argument or explanation of the current results. Second, VF asymmetries are usually determined by the interaction of a number of factors, and under certain circumstances some effects may be attenuated by others. Accordingly, Christman (1989) argued that increased eccentricity impairs LVF-RH performance more than RVF-LH performance, only if the features carried by higher frequencies are relevant for the task completion. In such cases, the reduced acuity attenuates the accessibility of high frequencies of stimuli and leads to a more severe impairment of the RH performance, because "its preferred range of lower frequencies is not sufficient for a task performance and the RH may have been less able than the LH to operate efficiently on the remaining high frequencies" (Christman, 1989, p. 242). Therefore, given that the LANT, for its effective completion, requires primarily processing of high spatial frequencies (cf. Chokron et al., 2000), the increased eccentricity should rather lead to a RVF-LH advantage.

To sum up, the LVF advantage observed in the current study seems to originate mainly from the hemispheric asymmetry of attentional networks. Still, the perceptual factors also may have influenced the observed asymmetries to some extent, although they would rather entail the LVF disadvantage. In such a case, the perceptual asymmetries would have been weaker and thereby overridden by the attentional asymmetries.

\subsection{Methodological issues}

\subsubsection{Lateralized vs. foveal stimulation}

With our interpretation of the results, we attempt to contribute to a synthesis of previous literature, bringing together behavioral and imaging data. However, the vast majority of imaging studies on the alerting and executive networks were carried out using a foveal presentation of stimuli, whereas almost all behavioral data concerning the attentional asymmetries were collected using a visual half-field methodology (cf. Bourne, 2006), usually with unilateral presentations of stimuli ${ }^{2}$. This raises a question of whether the behavioral and imaging data reflect the same underlying phenomena, and whether generalized conclusions can be inferred from the two kinds of data.

If a stimulus is presented on the fovea, both hemispheres get immediate access to it and certain aspects of information are usually processed by the more competent or more efficient hemisphere (Dien, 2009; Hellige et al., 2010). However, for stimuli presented laterally, there are at least two possible information processing scenarios accounted in the literature ${ }^{3}$. According to the direct access model (Zaidel, 1983), peripheral information is processed by the hemisphere that gets access to it first. In such cases, VF asymmetry is observed due to differences in the efficiency of the hemispheres in dealing with particular types of tasks. However, if one or more key components of a particular mechanism or system are located only in one hemisphere, the information presented to the ipsilateral hemifield has to be relayed by the corpus callosum, as predicted by the callosal relay model (Zaidel, 1983). In such cases, VF asymmetry occurs due to the additional time needed for interhemispheric transfer, as well as due to a possible degradation of the relayed information or interference with ongoing processes in the target hemisphere (see Moscovitch, 1986; Zaidel, 1983; Zaidel, Clarke, \& Suyenobu, 1990 for a review of the two models). Consequently, a different pattern of hemispheric activation may be observed, depending on whether a task involves callosal relay or direct access processing mode. In the direct access tasks, foveal stimuli would involve stronger activation of the more competent hemisphere (Dien, 2009; Kinsbourne, 1993), whereas peripheral stimulation would provide stronger activation in the contralateral hemisphere (cf. Hemond, Kanwisher, \& Op de Beeck, 2007). The callosal relay tasks would instead entail similar patterns of hemispheric activation for left, right, and central stimulations, because in all these cases, processing of a particular type of information involves the same lateralized regions (Dien, 2009) (although the time course of such activation would be definitely different for LVF and RVF stimuli).

How can we then figure out which of the two models accounts for the attentional asymmetries? Certainly, some attentional processes can be explained by the direct access model (Zaidel, 1995). For example, split-brain studies demonstrate that both hemispheres have their own system of endogenous selection (Luck, Hillyard, Mangun, \& Gazzaniga, 1994; Mangun et al., 1994). On the other hand, attentional reorienting is a case of callosal relay, because part of the process is handled by the right hemisphere only, as suggested by a number of lesion, imaging and TMS studies (see Corbetta et al., 2008 for review; see also Chambers et al., 2004 for TMS evidence). Importantly, there are results suggesting that response inhibition and alerting can be accounted for as instances of callosal relay, as well. Chikazoe and colleagues (2007) showed, using a go-nogo antisaccade task, that involvement of the right inferior frontal regions in response inhibition, previously observed with foveal stimulation, is consistently present in the visual halffield task for both left and right VF stimulation (see Chikazoe et al., 2007, figure $4 \& 5$ ). Sturm et al. (2005), on the other hand, employed two alertness tasks, one with central targets and the other with lateralized stimulation, and consistently observed the right hemisphere alerting network's activation under alertness conditions in both tasks, regardless of VF stimulation and irrespective of activation of the orienting network (Sturm et al., 2005). As

\footnotetext{
2 This concern is much less related to imaging studies of orienting, because all of them have been carried out with decentralized stimuli, in most cases using left-right visual half-field presentations, even if the lateralization was not addressed directly.

${ }^{3}$ We omit here the studies of interhemispheric interaction and cooperation using bilateral presentations and more complex tasks, as they are less relevant for the current study.
} 
claimed by Dien (2009), hemispheric asymmetry that is not sensitive to a change of the stimulation side reflects the effects of callosal relay. If this holds true, comparing results across visual half-field behavioral studies and the imaging studies with central presentations seems to be legitimate. However, for more reliable conclusions, further imaging studies with direct comparisons of foveal and lateralized stimulations are needed, which may offer a more coherent insight into the nature of attentional asymmetries.

\subsubsection{Fixation control}

Similarly to many behavioral visual half-field studies (see Bourne, 2006; Moscovitch, 1986), including the previous LANT studies (Greene et al., 2008; Poynter et al., 2010), we did not monitor participants' eye movement. Without eye tracking participants would not always keep appropriate fixation, however, excessive eye movement seems rather unlikely, as every participant was carefully instructed about the importance of correct fixation. As pointed out by Moscovitch (1986), there is evidence that instruction may suffice to provide proper fixation in the majority of normal healthy volunteers (Jones \& Santi, 1978; Posner, Nissen, \& Ogden, 1978). This seems to be further confirmed, for instance, by the fact that the visual half-field RSVP task reveals the same VF asymmetries both with and without online eye movement monitoring (Verleger et al., 2009; Verleger et al., 2011; Śmigasiewicz et al., 2010). Still, as we cannot definitely rule out possibility of incorrect fixation, the lack of fixation control has to be taken into account as a potential weakness of the present study.

\subsection{Concluding remarks}

The paper reports the LVF advantage in reorienting of attention and resolution of conflict. The results have already been replicated in several subsequent experiments (Asanowicz \& Wolski, 2008; Asanowicz \& Wolski, 2009). We have also successfully employed the LANT to investigate individual differences in the efficiency of attentional networks (Marzecová, Asanowicz, Krivá, \& Wodniecka, submitted for publication; Tao, Marzecová, Taft, Asanowicz, \& Wodniecka, 2011). While maintaining all the advantages of the ANT (Fan et al., 2002) and of the original LANT (Greene et al., 2008), the current task allows us to reliably measure VF asymmetries in terms of both RT and ERR. Nevertheless, further improvements are needed, such as differentiation of distinct aspects of alertness (cf. Posner, 2008). So far, we have been focusing on behavioral measures of attentional asymmetries. Further studies should supplement these with more direct measures of brain activity to investigate the relation between neural networks' asymmetries and cognitive performance, attempting to shed light on how "the structure of the brain determines the structure of the mind" (Zaidel, 1995, p. 491).

\section{Acknowledgments}

The third Author, Prof. Piotr Jaśkowski regretfully passed away during the preparation of this paper. We want to acknowledge the great role he played not only as a contributor but also as a spiritus movens of this and other Projects, a passionate researcher, and great friend we will all miss greatly. We thank the editor and the reviewers for their many constructive comments. Anna Marzecová was supported by a scholarship from the Foundation for Polish Science.

\section{References}

Abrams, J., Barbot, A., \& Carrasco, M. (2010). Voluntary attention increases perceived spatial frequency. Attention, Perception \& Psychophysics, 72(6), 1510-1521.
Aron, A. R., Robbins, T. W., \& Poldrack, R. A. (2004). Inhibition and the right inferior frontal cortex. Trends in Cognitive Sciences, 8(4), 170-177.

Asanowicz, D., \& Wolski, P. (2008). Spatial location uncertainty as modifier of attentional asymmetries [abstract]. In B. C. Love, K. McRae, \& V. M. Sloutsky (Eds.), Proceedings of the 30th annual conference of the cognitive science society (pp. 2039). Austin, TX: Cognitive Science Society.

Asanowicz, D., \& Wolski, P. (2009). Interhemispheric relations in attention evidenced by the lateralized attention network test (LANT) [abstract]. Acta Neurobiologiae Experimentalis, 69(3), 368.

Badre, D., \& Wagner, A. D. (2007). Left ventrolateral prefrontal cortex and the cognitive control of memory. Neuropsychologia, 45(13), 2883-2901.

Beaton, A., \& Blakemore, C. (1981). Orientation selectivity of the human visual system as a function of retinal eccentricity and visual hemilield. Perception, 10, 273-283.

Belanger, H. G., \& Cimino, C. R. (2002). The lateralized stroop: A meta-analysis and its implications for models of semantic processing. Brain and Language, 83(3), 384-402.

Blanca, M. J., Zalabardo, C., Gari-Criado, F., \& Siles, R. (1994). Hemispheric differences in global and local processing dependent on exposure duration. Neuropsychologia, 32, 1343-1351.

Boles, D. B., \& Karner, T. A. (1996). Hemispheric differences in global versus local processing: Still unclear. Brain and Cognition, 30(2), 232-243.

Botvinick, M. M., Cohen, J. D., \& Carter, C. S. (2004). Conflict monitoring and anterior cingulate cortex: An update. Trends in Cognitive Sciences, 8(12), 539-546.

Bourne, V. J. (2006). The divided visual field paradigm: Methodological considerations. Laterality, 11(4), 373-393.

Bradshaw, G. J., Hicks, R. E., \& Rose, B. (1979). Lexical discrimination and letterstring identification in the two visual fields. Brain and Language, 8(1), 10-18.

Bunge, S. A., Dudukovic, N. M., Thomason, M. E., Vaidya, C. J., \& Gabrieli, J. D. (2002) Immature frontal lobe contributions to cognitive control in children: Evidence from fMRI. Neuron, 33(2), 301-311.

Callejas, A., Lupiáñez, J., \& Tudela, P. (2004). The three attentional networks: On their independence and interactions. Brain and Cognition, 54(3), 225-227.

Callejas, A., Lupiáñez, J., Funes, M., \& Tudela, P. (2005). Modulations among the alerting, orienting and executive control networks. Experimental Brain Research, 167(1), 27-37.

Carrasco, M., Ling, S., \& Read, S. (2004). Attention alters appearance. Nature Neuroscience, 7(3), 308-313.

Chambers, C. D., Bellgrove, M. A., Gould, I. C., English, T., Garavan, H., McNaught, E., et al. (2007). Dissociable mechanisms of cognitive control in prefrontal and premotor cortex. Journal of Neurophysiology, 98(6), 3638-3647.

Chambers, C. D., Payne, J. M., Stokes, M. G., \& Mattingley, J. B. (2004). Fast and slow parietal pathways mediate spatial attention. Nature Neuroscience, 7(3), 217-218.

Chiarello, C., Senehi, J., \& Soulier, M. (1986). Viewing conditions and hemisphere asymmetry for the lexical decision. Neuropsychologia, 24(4), 521-529.

Chikazoe, J., Konishi, S., Asari, T., Jimura, K., \& Miyashita, Y. (2007). Activation of right inferior frontal gyrus during response inhibition across response modalities. Journal of Cognitive Neuroscience, 19(1), 69-80.

Chokron, S., Bartolomeo, P., Colliot, P., Brickman, A. M., Tabert, M., Wei, T., et al (2003). Selective attention, inhibition for repeated events and hemispheric specialization. Brain and Cognition, 53(2), 158-161.

Chokron, S., Brickman, A. M., Wei, T., \& Buchsbaum, M. S. (2000). Hemispheric asymmetry for selective attention. Brain Research. Cognitive Brain Research, 9(1), 85-90.

Christman, S. (1987). Effects of perceptual quality on hemispheric asymmetries in visible persistence. Perception and Psychophysics, 41, 367-374.

Christman, S. (1989). Perceptual characteristics in visual laterality research. Brain and Cognition, 11(2), 238-257.

Corbetta, M., \& Shulman, G. L. (2002). Control of goal-directed and stimulus-driven attention in the brain. Nature Reviews. Neuroscience, 3(3), 201-215.

Corbetta, M., Kincade, J., Ollinger, J., McAvoy, M., \& Shulman, G. (2000). Voluntary orienting is dissociated from target detection in human posterior parietal cortex. Nature Neuroscience, 3(3), 292-297.

Corbetta, M., Kincade, M. J., \& Shulman, G. L. (2002). Two neural systems for visual orienting and the pathophysiology of unilateral spatial neglect. In H. O. Karnath, A. D. Milner, \& G. Vallar (Eds.), The cognitive and neural basis of spatial neglect (pp. 259-274). Oxford: Oxford University Press.

Corbetta, M., Miezin, F. M., Shulman, G. L., \& Petersen, S. E. (1993). A PET study of visuospatial attention. The Journal of Neuroscience: The Official Journal of the Society for Neuroscience, 13(3), 1202-1226.

Corbetta, M., Patel, G., \& Shulman, G. L. (2008). The reorienting system of the human brain: From environment to theory of mind. Neuron, 58(3), 306-324.

Correa, A. (2010). Enhancing behavioural performance by visual temporal orienting. In A. C. Nobre \& J. T. Coull (Eds.), Attention and Time (pp. 357-370). Oxford: Oxford University Press.

Coull, J. T., Frith, C. D., Büchel, C., \& Nobre, A. C. (2000). Orienting attention in time: Behavioural and neuroanatomical distinction between exogenous and endogenous shifts. Neuropsychologia, 38(6), 808-819.

Danckert, J., \& Ferber, S. (2006). Revisiting unilateral neglect. Neuropsychologia, 44(6), 987-1006.

Dien, J. (2009). A tale of two recognition systems: Implications of the fusiform face area and the visual word form area for lateralized object recognition models. Neuropsychologia, 47(1), 1-16.

Du, F., \& Abrams, R. A. (2010). Visual field asymmetry in attentional capture. Brain and Cognition, 72(2), 310-316. 
Eriksen, B. A., \& Eriksen, C. W. (1974). Effects of noise letters upon the identification of a target letter in a nonsearch task. Perception \& Psychophysics, 16(1), 143-149.

Evert, D. L., McGlinchey-Berroth, R., Verfaellie, M., \& Milberg, W. P. (2003). Hemispheric asymmetries for selective attention apparent only with increased task demands in healthy participants. Brain and Cognition, 53(1), 34-41.

Evert, D. L., \& Oscar-Berman, M. (2001). Selective attentional processing and the right hemisphere: Effects of aging and alcoholism. Neuropsychology, 15(4), 452-461.

Eviatar, Z. (1995). Reading direction and attention: Effects on lateralized ignoring. Brain and Cognition, 29(2), 137-150.

Fan, J., Flombaum, J., McCandliss, B., Thomas, K., \& Posner, M. (2003). Cognitive and brain consequences of conflict. Neuroimage, 18(1), 42-57.

Fan, J., Gu, X., Guise, K., Liu, X., Fossella, J., Wang, H., et al. (2009). Testing the behavioral interaction and integration of attentional networks. Brain and Cognition, 70(2), 209-220.

Fan, J., Kolster, R., Ghajar, J., Suh, M., Knight, R. T., Sarkar, R., et al. (2007). Response anticipation and response conflict: An event-related potential and functional magnetic resonance imaging study. The Journal of Neuroscience, 27(9), 2272-2282.

Fan, J., McCandliss, B., Fossella, J., Flombaum, J., \& Posner, M. (2005). The activation of attentional networks. Neuroimage, 26(2), 471-479.

Fan, J., McCandliss, B. D., Sommer, T., Raz, A., \& Posner, M. I. (2002). Testing the efficiency and independence of attentional networks. Journal of Cognitive Neuroscience, 14(3), 340-347.

Fernandez-Duque, D., \& Posner, M. I. (2001). Brain imaging of attentional networks in normal and pathological states. Journal of Clinical and Experimental Neuropsychology, 23(1), 74-93.

Finlay, D., \& Jenkins, P. (1980). Some factors affecting tachistoscopic letter recognition. Psychological Research, 42, 241-254.

Forster, K. I., \& Forster, J. C. (2003). DMDX: A windows display program with millisecond accuracy. Behavior Research Methods, Instruments, E Computers: A Journal of the Psychonomic Society, 35(1), 116-124.

Fox, M., Corbetta, M., Snyder, A., Vincent, J., \& Raichle, M. (2006). Spontaneous neuronal activity distinguishes human dorsal and ventral attention systems. Proceedings of the National Academy of Sciences of the United States of America, 103(26), 10046-10051.

Franzon, M., \& Hugdahl, K. (1987). Effects of speed vs. Accuracy in voccal reaction time to visual half-field presentations of incongruent (stroop) color-words Cortex; A Journal Devoted to the Study of the Nervous System and Behavior,, 23(4), 615-629.

Funnell, M. G., Corballis, P. M., \& Gazzaniga, M. S. (2003). Temporal discrimination in the split brain. Brain and Cognition, 53(2), 218-222.

Garavan, H., Ross, T. J., \& Stein, E. A. (1999). Right hemispheric dominance of inhibitory control: An event-related functional MRI study. Proceedings of the National Academy of Sciences of the United States of America, 96(14) 8301-8306.

Garavan, H., Ross, T. J., Murphy, K., Roche, R. A. P., \& Stein, E. A. (2002). Dissociable executive functions in the dynamic control of behavior: Inhibition, error detection, and correction. Neuroimage, 17(4), 1820-1829.

Goghari, V. M., \& MacDonald, A. W. (2009). The neural basis of cognitive control: Response selection and inhibition. Brain and Cognition, 71(2), 72-83.

Grabowska, A., \& Nowicka, A. (1996). Visual-Spatial-Frequency model of cerebral asymmetry: A critical survey of behavioral and electrophysiological studies. Psychological Bulletin, 120(3), 434-449.

Grabowska, A., Nowicka, A., \& Szatkowska, I. (1992). Asymmetry in visual evoked potentials to gratings registered in the two hemispheres of the human brain. Acta Neurobiologiae Experimentalis, 52(4), 239-249.

Greene, D. J., Barnea, A., Herzberg, K., Rassis, A., Neta, M., Raz, A., et al. (2008). Measuring attention in the hemispheres: The lateralized attention network test (LANT). Brain and Cognition, 66(1), 21-31.

Hampshire, A., Chamberlain, S. R., Monti, M. M., Duncan, J., \& Owen, A. M. (2010). The role of the right inferior frontal gyrus: Inhibition and attentional control. Neuroimage, 50(3), 1313-1319.

Hausmann, M. (2005). Hemispheric asymmetry in spatial attention across the menstrual cycle. Neuropsychologia, 43(11), 1559-1567.

Hausmann, M., Waldie, K. E., \& Corballis, M. C. (2003). Developmental changes in line bisection: A result of callosal maturation? Neuropsychology, 17(1), 155-160.

Hazeltine, E., Bunge, S. A., Scanlon, M. D., \& Gabrieli, J. D. (2003). MaterialDependent and material-independent selection processes in the frontal and parietal lobes: An event-related fMRI investigation of response competition. Neuropsychologia, 41(9), 1208-1217.

Hazeltine, E., Poldrack, R., \& Gabrieli, J. D. (2000). Neural activation during response competition. Journal of Cognitive Neuroscience, 12(2), 118-129.

Heilman, K. M. (1995). Attentional asymmetries. In R. J. Davidson \& K. Hugdahl (Eds.), Brain asymmetry (pp. 217-234). Cambridge, MA: The MIT Press.

Heilman, K. M., \& Van Den Abell, T. (1979). Right hemispheric dominance for mediating cerebral activation. Neuropsychologia, 17, 315-321.

Heilman, K. M., \& Van Den Abell, T. (1980). Right hemisphere dominance for attention: The mechanism underlying hemispheric asymmetries of inattention (neglect). Neurology, 30(3), 327-330.

Hellige, J. B. (1980). Effects of perceptual quality and visual field of probe stimulus presentation on memory search for letters. Journal of Experimental Psychology: Human Perception and Performance, 6(4), 639-651.

Hellige, J. B., \& Sergent, J. (1986). Role of task factors in visual field asymmetries. Brain and Cognition, 5(2), 200-222.
Hellige, J. B., \& Webster, R. (1979). Right hemisphere superiority for initial stages of letter processing. Neuropsychologia, 17(6), 653-660.

Hellige, J. B., Corwin, W. H., \& Jonsson, J. E. (1984). Effects of perceptual quality on the processing of human faces presented to the left and right cerebral hemispheres. Journal of Experimental Psychology: Human Perception and Performance, 10(1), 90-107.

Hellige, J. B., Laeng, B., \& Michimata, C. (2010). Processing asymmetries in the visual system. In K. Hugdahl \& Westerhausen (Eds.), The two halves of the brain (pp. 379-415). Cambridge, MA: The MIT Press.

Hemond, C. C., Kanwisher, N. G., \& Op de Beeck, H. P. (2007). A preference for contralateral stimuli in human object- and face-selective cortex. Plos One, 2(6), e574.

Holländer, A., Corballis, M. C., \& Hamm, J. P. (2005). Visual-field asymmetry in dualstream RSVP. Neuropsychologia, 43(1), 35-40.

Hopfinger, J. B., Buonocore, M. H., \& Mangun, G. R. (2000). The neural mechanisms of top-down attentional control. Nature Neuroscience, 3(3), 284-291.

Huster, R. J., Westerhausen, R., Kreuder, F., Schweiger, E., \& Wittling, W. (2007). Morphologic asymmetry of the human anterior cingulate cortex. Neuroimage, 34(3), 888-895.

Jones, B., \& Santi, A. (1978). Lateral asymmetries in visual perception with or without eye movements. Cortex, 14, 164-168.

Kinsbourne, M. (1987). Mechanisms of unilateral neglect. In M. Jeannerod (Ed.) Neurophysiological and neuropsychological aspects of spatial neglect (pp. 69-86). Amsterdam: Elsevier.

Kinsbourne, M. (1993). Orientational bias model of unilateral neglect: Evidence from attentional gradients within hemispace. In J. C. Marshall (Ed.), Unilateral neglect: Clinical and experimental studies (pp. 63-86). Hove: Erlbaum.

Kim, Y. H., Gitelman, D. R., Nobre, A. C., Parrish, T. B., LaBar, K. S., \& Mesulam, M. M. (1999). The large-scale neural network for spatial attention displays multifunctional overlap but differential asymmetry. Neuroimage, 9(3), 269-277.

Kitterle, F. L., Hellige, J. B., \& Christman, S. (1992). Visual hemispheric asymmetries depend on which spatial frequencies are task relevant. Brain and Cognition, 20(2), 308-314.

Konishi, S., Nakajima, K., Uchida, I., Kikyo, H., Kameyama, M., \& Miyashita, Y. (1999). Common inhibitory mechanism in human inferior prefrontal cortex revealed by event-related functional MRI. Brain: A Journal of Neurology, 122(Pt 5), 981-991.

Levy-Schoen, A. (1977). Form identification in peripheral vision. Optica Acta, 24 139-145.

Levy, B. J., \& Wagner, A. D. (2011). Cognitive control and right ventrolateral prefrontal cortex: Reflexive reorienting, motor inhibition, and action updating. Annals of the New York Academy of Sciences, 1224, 40-62.

Losier, B. J., \& Klein, R. M. (2004). Covert orienting within peripersonal and extrapersonal space. Young adults. Brain Research. Cognitive Brain Research, 19(3), 269-274.

Luck, S. J., Hillyard, S. A., Mangun, G. R., \& Gazzaniga, M. S. (1994). Independent attentional scanning in the separated hemispheres of split-brain patients. Journal of Cognitive Neuroscience, 6(1), 84-91.

Lupiáñez, J., \& Funes, M. J. (2005). Peripheral spatial cues modulate spatial congruency effects: Analysing the "locus" of the cueing modulation. European Journal of Cognitive Psychology, 17(5), 727-752.

Lütcke, H., \& Frahm, J. (2008). Lateralized anterior cingulate function during error processing and conflict monitoring as revealed by high-resolution fMRI. Cerebral Cortex, 18(3), 508-515.

Macaluso, E., \& Patria, F. (2007). Spatial re-orienting of visual attention along the horizontal or the vertical axis. Experimental Brain Research, 180(1), 23-34

MacLeod, C. (1991). Half a century of research on the stroop effect: An integrative review. Psychological Bulletin, 109(2), 163-203.

Macleod, J. W., Lawrence, M. A., McConnell, M. M., Eskes, G. A., Klein, R. M., \& Shore, D. I. (2010). Appraising the ANT: Psychometric and theoretical considerations of the attention network test. Neuropsychology, 24(5), 637-651.

Mangun, G. R., Luck, S. J., Plager, R., Loftus, W., Hillyard, S. A., Handy, T., et al. (1994). Monitoring the visual world: Hemispheric asymmetries and subcortical processes in attention. Journal of Cognitive Neuroscience, 6(3), 267-275.

Manly, T., Dobler, V. B., Dodds, C. M., \& George, M. A. (2005). Rightward shift in spatial awareness with declining alertness. Neuropsychologia, 43(12), 1721-1728.

Martin, M. (1979). Hemispheric specialization for local and global processing. Neuropsychologia, 17, 33-40.

Marzecová, A., Asanowicz, D., Krivá, L. \& Wodniecka, Z. (submitted for publication). The effects of bilingualism on efficiency and lateralization of attentional networks. Bilingualism, Language and Cognition.

Marzi, C., Natale, N., \& Anderson, B. (2002). Mapping spatial attention with reaction time in neglect patients. In H. O. Karnath, A. D. Milner, \& G. Vallar (Eds.), The cognitive and neural basis of spatial neglect (pp. 275-288). Oxford: Oxford University Press.

Mesulam, M. M. (1981). A cortical network for directed attention and unilateral neglect. Annals of Neurology, 10(4), 309-325.

Mesulam, M. M. (1999). Spatial attention and neglect: Parietal, frontal and cingulate contributions to the mental representation and attentional targeting of salient extrapersonal events. Philosophical Transactions of the Royal Society B: Biological Sciences, 354(1387), 1325-1346.

Milham, M. P., Banich, M. T., Webb, A., Barad, V., Cohen, N. J., Wszalek, T., et al (2001). The relative involvement of anterior cingulate and prefrontal cortex in attentional control depends on nature of conflict. Brain Research. Cognitive Brain Research, 12(3), 467-473. 
Moscovitch, M. (1986). Afferent and efferent models of visual perceptual asymmetries: Theoretical and empirical implications. Neuropsychologia, 24(1), 91-114.

Natale, E., Marzi, C. A., \& Macaluso, E. (2010). Right temporal-parietal junction engagement during spatial reorienting does not depend on strategic attention control. Neuropsychologia, 48(4), 1160-1164.

Nobre, A. C., Sebestyen, G. N., \& Miniussi, C. (2000). The dynamics of shifting visuospatial attention revealed by event-related potentials. Neuropsychologia, 38(7), 964-974.

Nobre, A. C., Sebestyen, G. N., Gitelman, D. R., Mesulam, M. M., Frackowiak, R. S., \& Frith, C. D. (1997). Functional localization of the system for visuospatial attention using positron emission tomography. Brain: A Journal of Neurology, 120(3), 515-533.

Okon-Singer, H., Podlipsky, I., Siman-Tov, T., Ben-Simon, E., Zhdanov, A., Neufeld, M. Y., et al. (2010). Spatio-Temporal indications of sub-cortical involvement in leftward bias of spatial attention. Neuroimage, 54(4), 3010-3020.

Okubo, M., \& Nicholls, M. E. R. (2008). Hemispheric asymmetries for temporal information processing: Transient detection versus sustained monitoring. Brain and Cognition, 66(2), 168-175.

Parasuraman, R. (1998). The attentive brain: Issues and prospects. In R. Parasuraman (Ed.), The attentive brain (pp. 3-15). Cambridge, MA: The MIT Press.

Paus, T., Otaky, N., Caramanos, Z., MacDonald, D., Zijdenbos, A., D'Avirro, D., et al. (1996). In vivo morphometry of the intrasulcal gray matter in the human cingulate, paracingulate, and superior-rostral sulci: Hemispheric asymmetries, gender differences and probability maps. The Journal of Comparative Neurology, 376(4), 664-673.

Polich, J. (1978). Hemispheric differences in stimulus identification. Perception and Psychophysics, 24, 49-57.

Polich, J., \& Aguilar, V. (1990). Hemispheric local/global processing revisited. Acta Psychologica, 74, 47-60.

Polich, J., DeFrancesco, D. P., Garon, J. F., \& Cohen, W. (1990). Hemispheric differences in visual search of simple line arrays. Psychological Research, 52(1), 54-61.

Posner, M. I. (1980). Orienting of attention. Quarterly Journal of Experimental Psychology, 32(1), 3-25.

Posner, M. I. (2008). Measuring alertness. Annals of the New York Academy of Sciences, 1129, 193-199.

Posner, M. I., Nissen, M. J., \& Ogden, W. C. (1978). Attended and unattended processing modes: The role of set for spatial location. In H. L. Pick \& I. J. Saltzman (Eds.), Modes of perceiving and processing information (pp. 137-157). Hillsdale, NJ: Lawrence Erlbaum Associates Inc.

Posner, M. I., \& Petersen, S. (1990). The attention system of the human brain. Annual Review of Neuroscience, 13, 25-42.

Posner, M. I., \& Rothbart, M. K. (2007). Research on attention networks as a model for the integration of psychological science. Annual Review of Psychology, 58, $1-23$.

Posner, M. I., Sheese, B., Odludas, Y., \& Tang, Y. (2006). Analyzing and shaping human attentional networks. Neural Networks, 19(9), 1422-1429.

Poynter, W., Ingram, P., \& Minor, S. (2010). Visual field asymmetries in attention vary with self-reported attention deficits. Brain and Cognition, 72(3), 355-361.

Reuter-Lorenz, P. A., Kinsbourne, M., \& Moscovitch, M. (1990). Hemispheric control of spatial attention. Brain and Cognition, 12, 240-266.

Rhodes, D. L., \& Robertson, L. C. (2002). Visual field asymmetries and allocation of attention in visual scenes. Brain and Cognition, 50(1), 95-115.

Rizzolati, G., \& Buchtel, H. (1977). Hemispheric superiority in reaction time to faces: A sex difference. Cortex, 13, 300-305.

Robertson, I. H. (2004). Examining attentional rehabilitation. In M. I. Posner (Ed.), Cognitive neuroscience of attention (pp. 407-419). NY: The Guilford Press.

Schmit, V., \& Davis, R. (1974). The role of hemispheric specialization in the analysis of stroop stimuli. Acta Psychologica, 38(2), 149-158.

Sergent, J. (1983a). The effects of sensory limitations on hemispheric asymmetries. Canadian Journal of Psychology, 37, 345-366.

Sergent, J. (1983b). Role of the input in visual hemispheric asymmetries. Psychological Bulletin, 93(3), 481-512.

Sharp, D. J., Bonnelle, V., De Boissezon, X., Beckmann, C. F., James, S. G., Patel, M. C., et al. (2010). Distinct frontal systems for response inhibition, attentional capture, and error processing. Proceedings of the National Academy of Sciences of the United States of America, 107(13), 6106-6111.
Shulman, G. L., Pope, D. L. W., Astafiev, S. V., McAvoy, M. P., Snyder, A. Z., \& Corbetta, M. (2010). Right hemisphere dominance during spatial selective attention and target detection occurs outside the dorsal frontoparietal network. The Journal of Neuroscience. The Official Journal of the Society for Neuroscience, 30(10), 3640-3651.

Siman-Tov, T., Mendelsohn, A., Schonberg, T., Avidan, G., Podlipsky, I., Pessoa, L. et al. (2007). Bihemispheric leftward bias in a visuospatial attention-related network. The Journal of Neuroscience. The Official Journal of the Society for Neuroscience, 27(42), 11271-11278.

Spalek, T. M., \& Hammad, S. (2005). The left-to-right bias in inhibition of return is due to the direction of reading. Psychological Science: A Journal of the American Psychological Society, 16(1), 15-18.

Sturm, W., \& Willmes, K. (2001). On the functional neuroanatomy of intrinsic and phasic alertness. Neuroimage, 14(1 Pt 2), S76-S84.

Sturm, W., de Simone, A., Krause, B. J., Specht, K., Hesselmann, V., Radermacher, I., et al. (1999). Functional anatomy of intrinsic alertness: Evidence for a frontoparietal-thalamic-brainstem network in the right hemisphere. Neuropsychologia, 37(7), 797-805.

Sturm, W., Schmenk, B., Fimm, B., Specht, K., Weis, S., Thron, A., et al. (2005). Spatial attention: More than intrinsic alerting? Experimental Brain Research. Experimentelle Hirnforschung. Expérimentation Cérébrale, 171(1), 16-25.

Śmigasiewicz, K., Shalgi, S., Hsieh, S., Möller, F., Jaffe, S., Chang, C.-C., et al. (2010) Left visual-field advantage in the dual-stream RSVP task and reading-direction: A study in three nations. Neuropsychologia, 48(10), 2852-2860.

Tabert, M. H., Chokron, S., Tang, C. Y., Wei, T., Brickman, A. M., \& Buchsbaum, M. S. (2000). Visual target detection paradigm for the study of selective attention. Brain Research Protocols, 6(1-2), 80-85.

Tao, L., Marzecová, A., Taft, M., Asanowicz, D., \& Wodniecka, Z. (2011). The efficiency of attentional networks in early and late bilinguals: The role of age of acquisition. Frontiers in Psychology, 2(123), 1-19.

Vandenberghe, R., Duncan, J., Arnell, K. M., Bishop, S. J., Herrod, N. J., Owen, A. M., et al. (2000). Maintaining and shifting attention within left or right hemifield Cerebral Cortex, 10(7), 706-713.

Vanderhasselt, M. A., De Raedt, R., \& Baeken, C. (2009). Dorsolateral prefrontal cortex and stroop performance. Tackling the lateralization. Psychonomic Bulletin and Review, 16(3), 609-612.

Verfaellie, M., Bowers, D., \& Heilman, K. M. (1988). Hemispheric asymmetries in mediating intention, but not selective attention. Neuropsychologia, 26(4), 521-531.

Verleger, R., Sprenger, A., Gebauer, S., Fritzmannova, M., Friedrich, M., Kraft, S., et al (2009). On why left events are the right ones: Neural mechanisms underlying the left-hemifield advantage in rapid serial visual presentation. Journal of Cognitive Neuroscience, 21(3), 474-488.

Verleger, R., Smigasiewicz, K., \& Möller, F. (2011). Mechanisms underlying the left visual-field advantage in the dual stream RSVP task: Evidence from N2pc, P3, and distractor-evoked VEPs. Psychophysiology, 48(8), 1096-1106.

Wainwright, A., \& Bryson, S. E. (2005). The development of endogenous orienting: Control over the scope of attention and lateral asymmetries. Developmental Neuropsychology, 27(2), 237-255.

Weekes, N. Y., \& Zaidel, E. (1996). The effects of procedural variations on lateralized stroop effects. Brain and Cognition, 31(3), 308-330.

Whitehead, R. (1991). Right hemisphere processing superiority during sustained visual attention. Journal of Cognitive Neuroscience, 3(4), 329-334.

Woldorff, M. G., Hazlett, C. J., Fichtenholtz, H. M., Weissman, D. H., Dale, A. M., \& Song, A. W. (2004). Functional parcellation of attentional control regions of the brain. Journal of Cognitive Neuroscience, 16(1), 149-165.

Yan, H., Zuo, X.-N., Wang, D., Wang, J., Zhu, C., Milham, M. P., et al. (2009). Hemispheric asymmetry in cognitive division of anterior cingulate cortex: A resting-state functional connectivity study. Neuroimage, 47(4), 1579-1589.

Zaidel, E. (1983). Disconnection syndrome as a model for lateral effects in the normal brain. In J. B. Hellige (Ed.), Cerebral hemisphere asymmetry: Method. Theory, and application (pp. 95-151). New York, NY: Praeger Press.

Zaidel, E. (1995). Interhemispheric transfer in the split brain: Long-Term status following complete cerebral commissurotomy. In R. J. Davidson \& K. Hugdahl (Eds.), Brain asymmetry (pp. 491-532). Cambridge, MA: The MIT Press.

Zaidel, E., Clarke, J. M., \& Suyenobu, B. (1990). Hemispheric independence: A paradigm case for cognitive neuroscience. In A. B. Scheibel \& A. F. Wechsler (Eds.), Neurobiology of higher cognitive functions (pp. 297-355). New York, NY: The Guilford Press. 